KINERJA Jurnal Ekonomi dan Bisnis

Vol. 3 No. 1 - Desember 2020

\title{
PENGARUH BRAND AMBASSADOR DAN KOREAN WAVE TERHADAP MINAT BELANJA ONLINE MELALUI MARKETPLACE TOKOPEDIA
}

\author{
Yayan Hendayana, Ni’matul Afifah \\ Fakultas Ekonomi dan Bisnis Universitas Islam As-Syafi'iyah, Jakarta \\ Yayan_ha.feb@uia.ac.id; Afifahifah271198@gmail.com
}

\begin{abstract}
This study aims to determine the effect of Brand Ambassador and Korean Wave on Online Shopping Interests. The study was conducted on regular students of the As-Syafi'iyah Islamic University and 96 respondents were obtained. Hypothesis testing uses validity and reliability tests. Normality test, multicolliniarity test and heterokedasticity test. The analysis conducted was regression and correlation analysis, coefficient of determination and t test. Based on the results of testing and discussion, partially Brand Ambassador has a positive and significant effect on Online Shopping Interests with a significance level of $0.006<0.05$ and tcount 2.089> 1.985. Partially Korean Wave has a positive and significant effect on Online Shopping Interests with a significance level of $0.015<0.05$ and tcount 2.384> 1.985. The coefficient of determination (R2) of 0.274 means that the percentage contribution of the influence of Brand Ambassador and Korean Wave to Online Shopping Interests is $27.4 \%$ and the remaining $72.6 \%$ comes from other variables not examined.
\end{abstract}

Keywords: Brand Ambassador, Korean Wave, Online Shopping Interes 


\begin{abstract}
Abstrak
Penelitian ini bertujuan untuk mengetahui pengaruh Brand Ambassador dan Korean Wave terhadap Minat Belanja Online. Penelitian dilakukan pada mahasiswa reguler Universitas Islam As-Syafi'iyah dan didapatkan responden sebanyak 96. Pengujian hipotesis menggunakan uji validitas dan reliabilitas. Uji normalitas, uji multikoleniaritas dan uji heterokedastisitas. Analisis yang dilakukan adalah analisis regresi dan korelasi, koefisien determinasi dan uji t. Berdasarkan hasil pengujian dan pembahasan, secara parsial Brand Ambassador berpengaruh positif dan signifikan terhadap Minat Belanja Online dengan tingkat signifikansi sebesar 0,006 $<0,05$ dan $t_{\text {hitung }} 2,089>1,985$. Secara parsial Korean Wave berpengaruh positif dan signifikan terhadap Minat Belanja Online dengan tingkat signifikansi sebesar $0,015<0,05$ dan $t_{\text {hitung }} 2,389>1,985$. Koefisien determinasi $\left(\mathrm{R}^{2}\right)$ sebesar 0,274 artinya persentase sumbangan pengaruh Brand Ambassador dan Korean Wave terhadap Minat Belanja Online sebesar 27,4\% dan sisanya $72,6 \%$ berasal dari variabel lain yang tidak diteliti.
\end{abstract}

Kata kunci : Brand Ambassador, Korean Wave, Minat Belanja Online.

\title{
PENDAHULUAN
}

\section{LATAR BELAKANG}

Pertumbuhan dalam dunia usaha membawa akibat timbulnya persaingan usaha yang ketat. Terbentuklah Marketplace Tokopedia yang menjadi sarana bagi para penjual untuk menawarkan produknya secara online, dan bagi para konsumen untuk memudahkan dalam memenuhi kebutuhan.

Tokopedia selalu menjadi 3 ranking teratas dari situs terbaik di Indonesia dari tahun 2016-2019. Tokopedia menjadi e-commerce dengan rata-rata pengunjung / Monthly Active User (MAU) terbanyak tiap bulan selama tahun 2019, menurut data yang dilansir dari solutech global, Tokopedia merupakan marketplace yang memiliki pengunjung paling banyak. Berikut daftar Marketplace 5 besar terbaik yang ada di Indonesia :

Tabel 1

Daftar 5 marketplace terbaik 2019

\begin{tabular}{|c|c|c|c|c|c|c|c|}
\hline Toko Online & $\begin{array}{l}\text { Pengunjung } \\
\text { Web/bln }\end{array}$ & $\begin{array}{c}\text { Rank } \\
\text { Appstore }\end{array}$ & $\begin{array}{c}\text { Rank } \\
\text { Playstore }\end{array}$ & Twitter & IG & FB & $\begin{array}{c}\text { Jml } \\
\text { Karyawan }\end{array}$ \\
\hline 1. Tokopedia & 140.414 .500 & $\# 2$ & $\# 2$ & 205.070 & 1.263 .800 & 6.135 .250 & 3.144 \\
\hline 2. Shopee & 90.705 .300 & \#1 & $\# 1$ & 85.440 & 2.616 .800 & 14.804 .290 & 3.017 \\
\hline 3. Bukalapak & 89.765 .800 & \#4 & \#4 & 168.260 & 832.460 & 2.425 .880 & 2.696 \\
\hline 4. Lazada & 49.620 .200 & \#3 & \#3 & 369.840 & 1.332 .780 & 28.413 .580 & 2.289 \\
\hline 5. Blibli & 38.435 .000 & \#6 & \#6 & 485.030 & 822.130 & 8.349 .810 & 1.372 \\
\hline
\end{tabular}

Sumber : solutech global data di olah.

Berdasarkan tabel 1.2 diatas, Tokopedia menjadi marketplace terbaik pada tahun 2019 berdasarkan jumlah MAU yang mencapai 140.000.000. Akan tetapi, Tokopedia 
selalu kalah saing dengan marketplace lain, jika dilihat dari ranking appstore dan playstore, Shopee menjadi marketplace no 1, sedangkan Tokopedia berada diurutan kedua, begitupun berdasarkan pengguna Twitter, instagram dan facebook. Hal ini tentu menjadi masalah, mengapa Tokopedia yang memiliki jumlah MAU terbanyak belum menjadi ranking 1 dan hanya berada dalam 3 peringkat teratas dalam daftar marketplace terbaik.

Akan tetapi, Tokopedia selalu kalah saing dengan marketplace lain, jika dilihat dari ranking appstore dan playstore, Shopee menjadi marketplace no 1, sedangkan Tokopedia berada di urutan kedua, begitupun berdasarkan pengguna Twitter, instagram dan facebook. Hal ini tentu menjadi masalah, mengapa Tokopedia yang memiliki jumlah MAU terbanyak belum menjadi ranking 1 dan hanya berada dalam 3 peringkat teratas dalam daftar marketplace terbaik.

Pada tahun 2019, Tokopedia bekerjasama dengan boygrup BTS untuk menjadi Brand Ambassadornya, dan memanfaatkan fenomena Korean Wave untuk menarik minat belanja konsumen.

Menurut Firmansyah (2018 : 137) Brand mabassador adalah "Seseorang yang mempunyai passion terhadap Brand dan dapat mempengaruhi atau mengajak konsumen untuk membeli atau menggunakan suatu produk". Menurut Wikipedia Korean Wave adalah : Hallyu atau Korean Wave [2] (Hangul: 한류Hanja: 韓流RR: HallyuMR: Hallyu. Korean Wave atau dalam bahasa Indonesia disebut Gelombang Korea merupakan istilah yang digunakan untuk menjelaskan mengenai budaya pop Korea yang menyebar secara cepat secara global dan diminati oleh berbagai negara di dunia sejak tahun 1990-an. Banyak orang-orang di berbagai negara tertarik untuk mempelajari mengenai budaya dan bahasa Korea. Minat pembelian merupakan perilaku konsumen sebagai respon dari ketertarikan konsumen untuk melakukan pembelian (Kotler dan Keller 2012).

Penelitian terdahulu yang dibuat oleh Bhara dan Syahida (2019, hasil penelitian ditemukan pengaruh positif dan signifikan dari Brand Ambassador Shopee yang saat itu dibintangi oleh Blackpink, sehingga dengan adanya Blackpink sebagai Brand Ambassador, akan menaikkan Minat Belanja Online bagi konsumen. penelitian terdahulu yang dibuat oleh Brilliani dkk, (2018), hasil dari penelitian ini bahwa Brand Ambassador dan Promosi Penjualan mempengaruhi Minat Beli Handphone LG G7 Thinq. 
Berdasarkan latar belakang diatas, peneliti tertarik melakukan penelitian dengan judul : "Pengaruh Brand Ambassador dan Korean Wave Terhadap Minat Belanja Online Melalui Marketplace Tokopedia".

\section{Perumusan Masalah}

Berdasarkan uraian yang telah dikemukakan diatas, maka permasalahan dapat dirumuskan sebagai berikut :

1. Apakah Brand Ambassador berpengaruh terhadap Minat Belanja Online melalui Marketplace Tokopedia?

2. Apakah Korean Wave berpengaruh terhadap Minat Belanja Online melalui Marketplace Tokopedia?

\section{Tujuan Penelitian}

Berdasarkan uraian diatas maka tujuan penelitian adalah :

1. Untuk mengetahui pengaruh Brand Ambassador terhadap Minat Belanja Online melalui Marketplace Tokopedia

2. Untuk menetahui pengaruh Korean Wave terhadap Minat Belanja Online melalui Marketplace Tokopedia

\section{TINJAUAN PUSTAKA}

\section{Minat Belanja Online}

Minat pembelian merupakan kecenderungan konsumen untuk mengambil atau memilih suatu produk yang diukur dengan tingkat kemungkinan konsumen untuk membeli produk tersebut.

Menurut Durianto (2013 : 58) Minat beli adalah "Keinginan untuk memiliki produk, minat beli akan timbul apabila seseorang konsumen sudah terpengaruh terhadap mutu dan kualitas dari suatu produk atau informasi seputar produk".

Minat pembelian adalah perilaku yang muncul sebagai respon terhadap objek yang menunjang semua input berupa informasi, membawa konsumen pada tahap saat seseorang tertarik dengan produk tersebut dan menunjukkan keinginan seseorang untuk memutuskan suatu pembelian (Kotler dan Keller 2012).

Menurut Joko dan Doni (2019 : 133) : 
Minat pembelian merupakan pemusatan perhatian terhadap sesuatu yang disertai perasaan senang terhadap barang yang menimbulkan keinginan dan perasaan meyakinkan bahwa barang tersebut mempunyai manfaat sehingga ingin memiliki barang tersebut dengan cara membayar atau menukar dengan barang.

\section{Indikator Minat Belanja Online :}

1). Minat Transaksional, yaitu kecenderungan konsumen untuk selalu membeli produk (barang dan jasa) yang dihasilkan perusahaan. 2). Minat Referensial, yaitu kecenderungan konsumen untuk mereferensikan produknya kepada orang lain. 3). Minat Transaksional, yaitu minat yang menggambarkan perilaku konsumen yang memiliki preferensi utama terhadap berbagai produk. 4). Minat Eksploratif, yaitu minat yang menggambarkan perilaku konsumen yang selalu mencari informasi mengenai produk dan nilai positif dari produk tersebut.

\section{Faktor-faktor Minat Belanja Online / Minat Beli :}

Menurut Abdurachman (2004), ada beberapa faktor yang mempengaruhi minat beli, diantaranya Faktor kualitas, Brand/Merek, kemasan, harga, ketersediaan barang, dan faktor acuan.

\section{Brand Ambassador}

Menurut Lea-Greenwood (2012:88) “A Brand Ambassador is a tool used by companies to communicate and connect with the public, regarding how them actually enhances sales".

Menurut Shimp \& Andrews (2010 : 250) Brand ambassador adalah :

Ikon budaya atau identitas, dimana mereka bertindak sebagai alat pemasaran yang mewakili suatu produk. Brand Ambassador merupakan orang yang mendukung suatu merek dari berbagai tokoh masyarakat popular.

Sedangkan menurut Gita dan Setyorini (2016) : "Brand Ambassador merupakan ikon budaya atau identitas yang bertindak sebagai alat pemasaran yang mewakili suatu pencapaian atau produk serta komodifikasi dan komersialisasi suatu produk". 


\section{Faktor-faktor Brand Ambassador :}

Menurut Shimp (dalam Sagia, 2018), proses pemilihan Brand Ambassador memiliki pertimbangan berdasarkan urutan kepentingannya, yaitu : Kredibiltas, Kesesuaian Selebriti dengan Masyarakat, Kesesuaian Selebriti dengan Brand, dan daya tarik selebriti serta pertimbangan lainnya.

\section{Indikator Brand Ambassador :}

1). Atractiveness (Daya Tarik), meliputi sejumlah karakteristik yang dapat dilihat khalayak dalam diri pendukung, Penampilan menarik, dan pengetahuan yang tinggi mengenai produknya dapat membentuk kesan positif dan kepercayaan pada konsumen. 2). Trustworthiness (Kepercayaan), Konsumen cenderung memiliki kepercayaan dan ketertarikan terhadap selebriti dan tokoh masyarakat sebagai Brand Ambassador karena memiliki indikator-indikator penting, sehingga dapat mempengaruhi konsumen. 3). Expertise (Keahlian), mengacu pada pengetahuan, pengalaman, atau keterampilan yang dimiliki seseorang.

\section{Korean Wave}

Menurut sosiolog john lie dalam Lee and Nornes (2015: 7) menyatakan : In this regard, acutely discussed 3 factors that have brought K-Pop to the world. 1. K-Pop filled a niche between the "urbanized and sexualize" american pop music and more local. national traditions of popular music and K-Pop. 2. the korean state has backed the korean wave and K-Pop. lastly, K-Pop has high production values.

Berdasarkan teori diatas, ada 3 faktor yang telah membawa K-pop ke dunia. Pertama, K-pop mengisi ceruk antara musik pop Amerika "urban dan seksual" dan lebih lokal. tradisi nasional musik populer dan K-Pop. Kedua, Negara korea telah mendukung perkembangan hallyu dan K-Pop. Terakhir, K-Pop memiliki nilai produksi tinggi.

Menurut Korean Culture and Information Service (2011 : 11) "The term "Korena Wave" (Hallyu; Korea) was coiner by the chinese press a little more than a decade ago to refer the popularity of Korean Pop culture in China." 


\section{Faktor-faktor Korean Wave}

Menurut (Hyejung, 2010) Korean Wave adalah "a sudden upsurge of Korean popular culture, including television dramas, films, popmusic (hereafter, K-pop) and online games". Faktor-faktor korean wave adalah K-Pop, K-Drama, K-Cosmetic, dan KFashion.

\section{Indikator Korean Wave}

Menurut Sumiati (2019), Indikator-indikator dalam Korean Wave adalah : 1). Pemahaman (Understanding), yaitu memahami sifat dan arti keanekaragaman dan multikultularisme. 2). Sikap dan Perilaku (Attitude and Behavior), yaitu evaluasi konsumen atas kemampuan atribut suatu produk atau merek alternatif untuk memenuhi kebutuhan dalam perilaku pembelian konsumen. 3). Persepsi (Perception), yaitu proses bagaimana individu memilih, mengorganisasikan dan memberikan kesan serta informasi untuk menciptakan gambaran sesuatu yang memiliki arti.

\section{Kerangka Pemikiran}

\section{Hubungan Brand Ambassador dengan Minat Belanja Onlie}

Minat pembelian merupakan perasaan senang terhadap suatu produk yang menimbulkan keinginan untuk membeli produk tersebut, maka jika Brand Ambassador yang digunakan merupakan artis yang memiliki citra dan penilaian yang baik dimata konsumen, saat sang artis menggunakan produk tersebut, mengiklankan, menginformasikan, serta mengajak kepada konsumen untuk menggunakan produk tersebut, maka konsumen akan lebih tertarik untuk membeli produk.

Menurut Joko dan Doni (2019 : 133) : Minat pembelian merupakan pemusatan perhatian terhadap sesuatu yang disertai perasaan senang terhadap barang yang menimbulkan keinginan dan perasaan meyakinkan bahwa barang tersebut mempunyai manfaat sehingga ingin memiliki barang tersebut dengan cara membayar atau menukar dengan barang.

Menurut Shimp \& Andrews (2010 : 250). Brand ambassador adalah : Ikon budaya atau identitas, dimana mereka bertindak sebagai alat pemasaran yang mewakili suatu produk. Shimp mengatakan bahwa Brand ambassador merupakan orang yang mendukung suatu merek dari berbagai tokoh masyarakat popular. 
Menurut peneliti, dalam menarik perhatian konsumen untuk memutuskan pembelian, Brand Ambassador menjadi alasan bagi para konsumen terutama fans dan penyuka dari artis yang dikontrak menjadi Brand Ambassador sebuah merek atau produk. Penobatan sebagai Brand Ambassador suatu perusahaan atau produk, diharapkan dapat menarik minat konsumen untuk belanja.

Menurut penelitian Lestari (2019), Brand Ambassador berpengaruh signifikan terhadap citra merek. Menurut penelitian Sagia (2018) Brand Ambassador berpengaruh positif dan signifikan terhadap keputusan pembelian skincare produk aloe vera

Menurut Shimp \& Andrews (2010 : 250). Brand ambassador adalah "Ikon budaya atau identitas, dimana mereka bertindak sebagai alat pemasaran yang mewakili suatu produk". Shimp mengatakan bahwa Brand ambassador merupakan orang yang mendukung suatu merek dari berbagai tokoh masyarakat popular.

Menurut teori di atas, individu atau kelompok yang dikontrak sebagai Brand Ambassador merupakan tokoh dari perwakilan masyarakat yang populer, dalam hal ini adalah artis, yang kemudian dikontrak oleh perusahaan sebagai Brand Ambassador dengan harapan meningkatkan minat belanja bagi konsumen khususnya melalui marketplace online. Menurut penelitian Bhara dan Syahida (2019), Brand Ambassador secara signifikan berpengaruh terhadap Minat Belanja Online.

\section{Hubungan Korean Wave dengan Minat Belanja Online}

Korean Wave adalah istilah yang diberikan untuk tersebarnya budaya pop Korea secara global di berbagai negara di dunia sejak tahun 1990-an. Umumnya Hallyu memicu banyak orang-orang di negara tersebut untuk mempelajari Bahasa Korea dan kebudayaan Korea.

Menurut Morissan (2010 : 128) : Faktor yang paling luas dan abstrak yang mempengaruhi keputusan pembelian konsumen adalah faktor budaya yang merupakan suatu komplekitas dari makna, nilai norma, dan tradisi yang dipelajari dan dibagi oleh anggota suatu masyarakat. Menurut Sagia (2018), Korean Wave berpengaruh positif dan signifikan terhadap keputusan pembelian skincare produk aloe vera. Menurut Lestari (2019) Korean Wave berpengaruh signifikan terhadap citra merek dan keputusan pembelian 
Menurut peneliti, untuk menarik minat belanja konsumen yang akan mempengaruhi keputusan pembelian konsumen, faktor budaya bisa dimanfaatkan oleh produsen. Karena budaya merupakan suatu kompleksitas dari makna, nilai norma, dan tradisi yang dipelajari. Berbagai macam budaya dari daerah dan negara yang tersebar diseluruh penjuru dunia, yang mana budaya ada yang diterima oleh masyarakat luas dan disukai sehingga menjadi kebiasaan bagi masyarakat yang bukan penduduk asli dari tempat budaya tersebut berasal. Sementara menurut Anshory (2013 : 67) : Budaya adalah sistem yang memilki koherensi. Bentuk-bentuk simbolis yang berupa benda, kata, lagu, mite, sastra, lukisan, nyanyian, musik, kepercayaan, mempunyai kaitan erat dengan konsepkonsep epistemologis dari sistem pengetahuan masyarakatnya

Berdasarkan teori diatas, individu atau kelompok yang menyukai minimal 1 dari suatu budaya seperti benda, kata, lagu, mite, sastra, lukisan, musik, dan kepercayan merupakan tanda bahwa individu atau kelompok tersebut sudah menerima atau terkena dampak tersebuarnya budaya dari daerah atau negara lain. Menurut Sumiati (2019), Budaya populer Korean Wave berpengaruh signifikan dan positif terhadap sikap dan minat beli konsumen.

Korean Wave merupakan istilah tersebarnya budaya pop Korea secara global di berbagai belahan negara di dunia yang dimulai sejak tahun 1990-an. Pada umumnya Hallyu memicu orang-orang di negara tersebut untuk mempelajari Bahasa Korea dan kebudayaan Korea seperti bahasa, cara berpakaian, cara berbicara, dan lain-lain.

Menurut penelitian Surya (2018), sikap terhadap drama korea, dan efek country of origin berpengaruh positif pada sikap terhadap produk Korea Selatan, dan sikap terhadap produk Korea Selatan berpengaruh positif terhadap minat beli konsumen. Berdasarkan uraian hubungan antar variabel tersebut, dapat digambarkan dalam bentuk bagan sebagai berikut : 


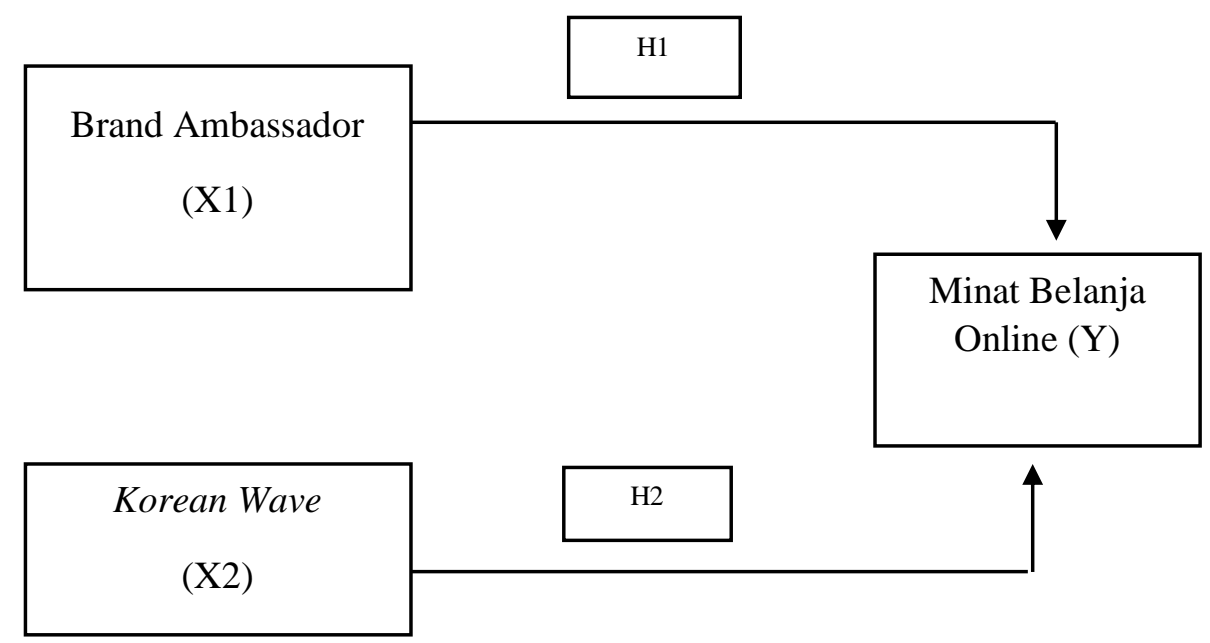

\section{Hipotesis}

H1 : Brand Ambassador berpengaruh terhadap Minat Belanja Online

$\mathrm{H} 2$ : Korean Wave berpengaruh terhadap Minat Belanja Online

\section{METODE PENELITIAN}

\section{Populasi, Sampel dan Sampling}

Populasi dalam penelitian ini adalah mahasiswa reguler Universitas Islam AsSyafi'iyah. Dengan menggunakan rumus lemeshow, didapat responden sebanyak 96, yang memenuhi syarat berdasarkan kriteria yang telah ditentukan.

\section{Teknik Pengumpulan Data}

Data merupakan data primer. Penulis menggunakan teknik pengumpulan data dengan cara menyebarkan kuisioner secara online kepada para responden.

\section{Metode Analisis Data}

Untuk menganalisis hubungan antara variabel dependent dan independent, penulis menggunakan analisis regresi sederhana dan berganda, kemudian analisis korelasi sederhana dan berganda. Analisis dalam penelitian ini menggunakan SPSS Statistics 25. Kemudian melakukan uji kecocokan model regresi melalui koefisien determinasi. Dan terakhir melakukan pengujian Hipotesis yakni Uji T. 


\section{HASIL PENELITIAN}

\section{Uji T (Parsial)}

Uji T (Parsial) digunakan untuk menguji seberapa jauh pengaruh masing-masing variabel independen terhadap variabel dependent. Pengambilan keputusan berdasarkan nilai $t_{\text {hitung }}$ dan nilai kritis sesuai dengan tingkat signifikan yaitu 0,05 .

1) Jika nilai $t_{\text {hitung }}>t_{\text {tabel }}$ maka $\mathrm{H} 0$ ditolak

2) Jika nilai $t_{\text {hitung }}<t_{\text {tabel }}$ maka $\mathrm{H} 0$ diterima

Tabel 2

Hasil Uji T

\begin{tabular}{|c|c|c|c|c|c|c|}
\hline \multicolumn{7}{|c|}{ Coefficients $^{\mathrm{a}}$} \\
\hline \multirow{2}{*}{\multicolumn{2}{|c|}{ Model }} & \multicolumn{2}{|c|}{$\begin{array}{l}\text { Unstandardized } \\
\text { Coefficients }\end{array}$} & \multirow{3}{*}{$\begin{array}{c}\text { Standardized } \\
\text { Coefficients } \\
\text { Beta }\end{array}$} & \multirow{3}{*}{$\begin{array}{l}\mathrm{t} \\
5,667\end{array}$} & \multirow{3}{*}{$\begin{array}{l}\text { Sig. } \\
0,000\end{array}$} \\
\hline & & B & $\begin{array}{l}\text { Std. } \\
\text { Error }\end{array}$ & & & \\
\hline & (Constant) & 22,923 & 4,045 & & & \\
\hline 1 & Brand_Ambassador & 0,379 & 0,135 & 0,326 & 2,809 & 0,006 \\
\hline & Korean_Wave & 0,272 & 0,114 & 0,277 & 2,386 & 0,019 \\
\hline
\end{tabular}

\section{Pengaruh Brand Ambassador Terhadap Minat Belanja Online melalui Marketpace}

\section{Tokopedia}

Berdasarkan Uji t menunjukkan bahwa taraf signifikan Brand Ambassador sebesar $0,006<0,05$ dan $t_{\text {hitung }}$ sebesar 2,089 > 1,985 (dari daftar $\mathrm{T}$ tabel). Hasil penelitian ini mendukung hasil penelitian yang dilakukan oleh Bhara dkk (2019) yaitu Pengaruh Iklan "Shopee Blackpink Sebagai Brand Ambassador Terhadap Minat Belanja Online Mahasiswa. Dimana hasilnya menunjukkan bahwa Brand Ambassador berpengaruh terhadap Minat Belanja Online. Hal ini menunjukkan adanya keselarasan antara hasil penelitian sebelumnya dengan penelitian yaitu terdapat pengaruh Brand Ambassador terhadap Minat Belanja Online. 


\section{Pengaruh Korean Wave Terhadap Minat Belanja Online melalui Marketpace}

\section{Tokopedia}

Berdasarkan Uji t menunjukkan bahwa taraf signifikan signifikan Korean Wave sebesar $0,015<0,05$ dan thitung sebesar 2,389 > 1,985 (dari daftar T tabel).

Hasil penelitian ini mendukung hasil penelitian yang dilakukan oleh Sumiati (2019) "Dampak Etnosentrime dan Budaya Populer Terhadap Sikap Konsumen serta Implikasinya Terhadap Minat Beli Konsumen”. Hal ini menunjukkan adanya keselarasan antara hasil penelitian sebelumnya dengan penelitian, yaitu dapat pengaruh Korean Wave terhadap Minat Belanja Online.

\section{Koefisien Determinasi}

Koefisien determinasi (R2) sebesar 0,274 artinya persentase sumbangan pengaruh Brand Ambassador dan Korean Wave terhadap Minat Belanja Online sebesar 27,4\% dan sisanya $72,6 \%$ berasal dari variabel lain yang tidak diteliti.

\section{PENUTUP}

\section{Simpulan}

1) Terdapat pengaruh positif signifikan Brand Ambassador terhadap minat belanja oline melalui marketpace Tokopedia pada Mahasiswa Universitas Islam As-Syafi'iyah.

2) Terdapat pengaruh positif signifikan Korean Wave terhadap minat belanja oline melalui marketpace Tokopedia pada Mahasiswa Universitas Islam As-Syafi'iyah.

\section{Saran}

\section{Bagi Perusahaan}

1) Disarankan bagi perusahaan untuk meningkatkan promosi dengan iklan bertajuk BTS, untuk menarik konsumen khususnya penggemar K-Pop dan ARMY (Fanclub BTS).

Berdasarkan hasil pernyataan, yang memiliki persentase tertinggi adalah daya tarik pada Brand Ambassador, dengan persentase sebesar 70,8\%.

2) Disarankan bagi perusahaan untuk memberikan layanan lebih baik seperti promo, flash sale, dan lain-lain untuk menarik perhatian konsumen agar belanja online melalui Tokopedia. 
Berdasarkan hasil pernyataan responden, indikator minat preferensi memiliki persentase terendah yakni $70,67 \%$.

3) Disarankan bagi perusahaan, jika masa kontrak dengan Big Hit Entertainment sudah habis, perusahaan bisa memperpanjang kontrak dengan BTS supaya tetap menjadi Brand Ambassadornya, atau mencari Brand Ambassador lain asal Korea Selatan seperti boygrup/girlgrup, Aktor/Aktris drama, dll.

Berdasarkan angka indeks pada indikator pemahaman variabel Brand Ambassador sebesar 88,33 .

\section{Bagi Peneliti Selanjutnya}

1) Peneliti dapat memperbaiki keterbatasan yang ada dalam penelitian ini, dengan memperbanyak jumlah sampel dan cara cara pengambilan data untuk mendapatkan hasil yang menyeluruh.

2) Peneliti selanjutnya diharapkan dapat mengembangkan dan memasukkan variabel lain selain variabel Brand Image, dan Korean Wave yang berpengaruh terhadap minat beli online.

\section{DAFTAR PUSTAKA}

Lea-Greenwood, Gaynor. 2012. Fashion Marketing Communications E-book. Somerset, NJ, USA: Wiley.

Kim, D., Cho, S.-D., \& Jung, G. (2014). Wave Of Home Culture And MNC Performance. The Korean Wave (Hallyu). Wave Of Home Culture And MNC International Marketing In Rapidly Changing Environments, 193 - 216.

Kotler, P., \& Keller, K. L. (2012). Marketing Management. New Jersey: Pearson Prentice Hall.

Kotler, P., \& Keller, K. L. (2013). Manajemen Pemasaran. Jakarta: Erlangga.

Sciffman, Leon G, dan Kanuk, L, L. 2007. Costumer Behavior. Prentice Hall.

A, Rahayu. 2020. BTS Susah Move on. Araska, Yogyakarta

Alma Buchari. 2011. Manajemen Pemasaran dan pemasaran Jasa. Alfabeta. Bandung

Hery. 2019. Manajemen Pemasaran. PT Grasindo, Jakarta.

Prasetyo B, D. Febriani, N, S. Asmara, W,W. 2018. Komunikasi Pemasaran Terpadu (pendekatan tradisional hingga era media baru). Edisi 1, UB Press, Malang. 
Sunyoto, Danang. 2014. Praktik Riset Perilaku Konsumen. Center Of Academic Publishing Service, Jakarta

Tjiptono, Fandy. 2015. Strategi Pemasaran. Penerbit ANDI, Yogyakarta

Sugiyono. 2017. Metode Penelitian Kombinasi. Alfabeta, Bandung

Riyanto, S. dan Hatmawan, A,A. 2020. Manajemen, teknik, pendidikan dan eksperimen. Edisi 1, DEEPUBLISH, Yogyakarta.

Siregar, S. 2017. Metode penelitian luantitatif dilengkapi dengan perbandingan perhitungan manual dan spss. Edisi 1, KENCANA, Jakarta.

Korean culture and information service. 2011. The Korean Wave : A New Pop Culture Phenomenon. Ministry Of Culture, Sports and Tourism.

Yoon, J, T, and Jin, Y, D. 2014. The Korean Wave : Evolution, Fandom and Transnationality. Lexington Books.

Sangjoon, L. and Nornes, A, M. 2015. Hallyu 2.0 : The Korean Wave in The age of sicial media. Media Commons.

Brilianni. Kusniadji, S. dan Utami, L, S, S. 2018. Faktor-Faktor yang Mempengaruhi Minat Beli Smartphone LG G7 Thinq Pada Fans BTS di Jakarta BaratFaktorFaktor yang Mempengaruhi Minat Beli Smartphone LG G7 Thinq Pada Fans BTS di Jakarta Barat. Jurnal Komunikasi. Vol. 2, No. 2 : Hal 240-245.

Nurhablisyah dan Susanti, K. 2020. Fenomena BTS dalam iklan "Tokopedia", sebuah tinjauan budaya visual. Jurnal Magenta. Vol. 4, No. 1

Bhara, A, M. Dan Syahida, A, R. 2019. Pengaruh Iklan "Shopee Blackpink Sebagai Brand Ambassador Terhadap Minat Belanja Online Mahasiswa. Jurnal ilmu Sosial dan Politik. 8 (4).

Surya, C, E, P. 2018. Pengaruh efek country origin, sikap terhadap drama korea, dan sikap terhadap produk Korea Selatan pada niat beli konsumen dilihat dari usia konsumen.

Sumiati. 2019. Dampak Etnosentrime dan Budaya Populer Terhadap Sikap Konsumen serta Implikasinya Terhadap Minat Beli Konsumen. Jurnal Manajemen Bisnis dan Kewirausahaan. 4 (2) : 27-31.

Lestari, H. Sunarti. Bafadhal, A, S. 2019. Pengaruh Brand Ambassador Dan Korean Wave Terhadap Citra Merek Serta Dampaknya Pada Keputusan Pembelian" (Survei Online Pada Konsumen Innisfree Di Indonesia Dan China). Jurnal Administrasi Bisnis. 66 (1).

Sagia, A. 2018. Pengaruh Brand Ambassador, Brand Personality Dan Korean Wave Terhadap Keputusan Pembelian (Studi Pada Mahasiswa Pengguna Skincare Produk Nature Republic Aloe Vera Di Fakultas Ilmu Budaya Universias Sumatera Utara). Jurnal Manajemen.

Kharisma, G. 2019. Meninjau Peta E-commerce Indonesia di Awal 2019, Siapa Jadi Juara?. https://id.techinasia.com/peta-ecommerce-indonesia-q1-2019 diakses tanggal 20 Maret 2020. 
KINERJA Jurnal Ekonomi dan Bisnis

Vol. 3 No. 1 - Desember 2020

Fenalosa, A. 2018. Kilas Balik Ecommerce Platform di Indonesia Tahun 2018. https://iprice.co.id/trend/insights/kilas-balik-e-commerce-di-indonesia-tahun2018/ diakses tanggal 20 Maret 2020.

Rachamtunnisa. 2020. Survei: Tokopedia dan Shopee Adu Kuat Mendominasi. https://inet.detik.com/business/d-4872404/survei-tokopedia-dan-shopee-adukuat-mendominasi diakses tanggal 20 Maret 2020. 